\title{
Manufacturing of Al-Zr Thermal-resistant Alloys for Transmission Lines
}

\author{
A.T. Erturk ${ }^{a, *}$, E.A. Guven ${ }^{b}$, S. KArABAY ${ }^{b}$ \\ ${ }^{a}$ Kocaeli University, Ford Otosan Vocational School of Automotive, 41680, Kocaeli, Turkey \\ ${ }^{b}$ Kocaeli University, Engineering Fac., Mechanical Eng. Dept. 41380, Kocaeli, Turkey
}

\begin{abstract}
The present transmission lines of populous cities will have to be changed with an ability to work at higher temperatures without any weight and cross section changes. Innovative thermal-resistant alloy conductors (T-ACSR) operate in the range of about $150-200{ }^{\circ} \mathrm{C}$ instead of $75{ }^{\circ} \mathrm{C}$ which is the standard ACSR type conductor service temperature. In this study, the manufacturing procedure of $\mathrm{Al}-\mathrm{Zr}$ alloy wire, used as high-temperature conductor wires, have been introduced. The Al-Zr alloy has been cast in a permanent mold than being extruded to a diameter of $10 \mathrm{~mm}$ at $400{ }^{\circ} \mathrm{C}$. After that the extruded rods have been cold drawn to a diameter of $3.02 \mathrm{~mm}$. Elongation and tensile strength values of the cold drawn wire have been achieved by tensile test at elevated temperatures. Also, microstructural analysis and dispersion hardening procedure have been investigated. The results show that tensile strength and thermal-resistant property are improved by the addition of $\mathrm{Zr}$.
\end{abstract}

DOI: $10.12693 /$ APhysPolA.127.1292

PACS: 81.05.Bx, 88.80.H, 83.50.Uv, 81.70.Jb, 81.40.Ef, 81.70.Bt

\section{Introduction}

The industries in rapidly growing countries and changing habits of house consumption in extremely dense populations drive substantial increases in energy use. Residential and commercial power usage usually peaks around the early morning and the afternoon [1]. Besides, industrial power users need more energy for processing operations. Total consumer demand of different end-user types has been increasing day by day that is a very huge problem for developing countries all over the world. An idea that comes to mind is changing wires on transmission lines with greater sizes of diameters to solve this problem. When this route is followed that such an investment causes a heavy financial burden, and deadlock is inevitable for large developing countries in terms of area [2].

Another idea for resolving the problem is increasing current bearing capabilities of the wire materials, while retaining light weight characteristics [3-5]. Thus enlargement requirement of the conductor diameter is eliminated. While following this method basic obstacle is principally due to power lost through electrical resistance that converts inherently electric power into thermal energy, which raises the temperature on wire. Wire materials have to exhibit resistance as low as possible to reduce energy loss and maintaining their strength under higher temperatures. Current bearing properties are limited by the characteristic thermal capacity of wire material due to insufficient strength at high current levels [6]. All of the materials have resistance which is a physical characteristic basically depending on the type of elemental composition [3]. The aim of the present work is to exhibit a wire, which is made of aluminum alloy consist of

* corresponding author; e-mail: tamer.erturk@kocaeli.edu.tr
$\mathrm{Zr}$ that provide a thermal-resistant alloy for conductors with the best possible recrystallisation resistance. Thermal limitation of wire materials are exceeded through the usage of $\mathrm{Zr}$ inoculations in aluminum. Effect of annealing stage in manufacturing of Al-Zr alloy on mechanical and electrical properties has not been investigated yet in any study. For this purpose a comprehensive study of the effect of adding $\mathrm{Zr}$ to nearly pure $\mathrm{Al}$ has been carried out with a special focus on using the transmission lines. After casting alloy and forming it to a length of wire, tensile test and thermal-resistant properties at $120{ }^{\circ} \mathrm{C}$, electrical conductivity, microstructural and EDS analysis of the wires have been investigated. The results show that the ability of the $\mathrm{Zr}$ doped aluminum alloy maintains its electrical and mechanical properties at $120^{\circ} \mathrm{C}$.

\section{Experimental}

Al-Zr alloy studied in the work was prepared using commercial pure aluminum (99.66\%), and master alloy of $\mathrm{Al}-4.46 \% \mathrm{Zr}$ (mass fraction). Chemical specifications of the raw materials and alloy were given in Table I. After melting in an graphite crucible at $790{ }^{\circ} \mathrm{C}$, obtained Al$\mathrm{Zr}$ alloy was cast into a diameter of $30 \mathrm{~mm}$ and height of $50 \mathrm{~mm}$ billet by steel mold and cooled from the bottom with water sprey to avoid pore formation.

Alloy Compositions in Weight Percent.

TABLE I

\begin{tabular}{c|c|c|c|c|c}
\hline \hline Alloy & $\mathrm{Al}$ & $\mathrm{Zr}$ & $\mathrm{Si}$ & $\mathrm{Fe}$ & $\mathrm{Zn}$ \\
\hline Pure Al & 99.664 & $<0.003$ & 0.0570 & 0.1590 & 0.0090 \\
Al-Zr Master Alloy & 94.218 & 4.462 & 0.122 & 1.197 & 0.0015 \\
Al-\%0.32 Zr & 99.738 & 0.0318 & 0.0660 & 0.1540 & 0.0100
\end{tabular}

After that the Al-0.32\% $\mathrm{Zr}$ billet was extruded at $400{ }^{\circ} \mathrm{C}$ in a $10 \mathrm{~mm}$ diameter rod form and divided into two groups to investigate effect of the heat treatment. First group of $\mathrm{Al}-0.32 \% \mathrm{Zr}$ rod was annealed before cold drawn into a $3.02 \mathrm{~mm}$ diameter wire. Second group of $\mathrm{Al}-0.32 \% \mathrm{Zr}$ rod was annealed after cold drawn into a $3.02 \mathrm{~mm}$ diameter wire. Extrusion and drawing applications were performed with a DARTEC universal tensile testing equipment modified into a vertical extrusion 
press and drawing machine. A hydraulic cylinder with a load capacity of 60 tons was used to provide the load. The speed of the ram was $10 \mathrm{~mm} \mathrm{~s}^{-1}$. Annealing procedure was performed in forced air circulation in resistively heated furnace. Al- $0.32 \% \mathrm{Zr}$ alloy in rod for first group and wire form for second group were heated from room temperature at a rate of $50{ }^{\circ} \mathrm{C} / \mathrm{h}$ and kept at $400{ }^{\circ} \mathrm{C}$ for 48 hours.

Cold moulded sections of the wire parts were grinded by using the Metcon Forcipol 2V rotating polishing machine with various grades of $\mathrm{SiC}$ papers up to 2400 grid. Specimens were subjected to fine polishing by using $1 \mu \mathrm{m}$ diamond paste and then final polishing by using $0.06 \mu \mathrm{m}$ colloidal silica suspension. Specimens were cleaned with water and dried with acetone before etching. Polished specimens were immersed into an etchant (45 $\left.\mathrm{ml} \mathrm{H}_{2} \mathrm{O}_{5}+45 \mathrm{ml}(70 \%) \mathrm{HNO}_{3}+10 \mathrm{ml}(48 \%) \mathrm{HF}\right)$ for 5 seconds and washed with warm water in order to neutralize residual of etchant. Nikon MA100 optical microscope was used for microstructural examination. High temperature performance of two groups (annealed after and before cold drawn) $\mathrm{Al}-0.32 \% \mathrm{Zr}$ wires were determined by tensile test at $120^{\circ} \mathrm{C}$. Tensile tests were performed with Shimadzu AG-X universal tensile test machine and coupled thermostatic chamber of it. Microanalysis was performed with a FEI Quanta 50 SEM/EDS equipment, and the specimens were in the unetched condition. Electrical properties of the conductors were determined with a GW Instek PPH 1503 linear DC power supplier.

\section{Results}

When conductors are used in transmission lines under a higher electrical transport condition, they are subject to minimum dead load and extra another external forces (lightning, wing, galloping etc.) [7, 8]. Mechanical properties of the wires were established for a higher demand condition by tensile test at $120{ }^{\circ} \mathrm{C}$. The tests were carried out on 3.02 diameter wires of uniform cross section. The results can be seen in Fig. 1.

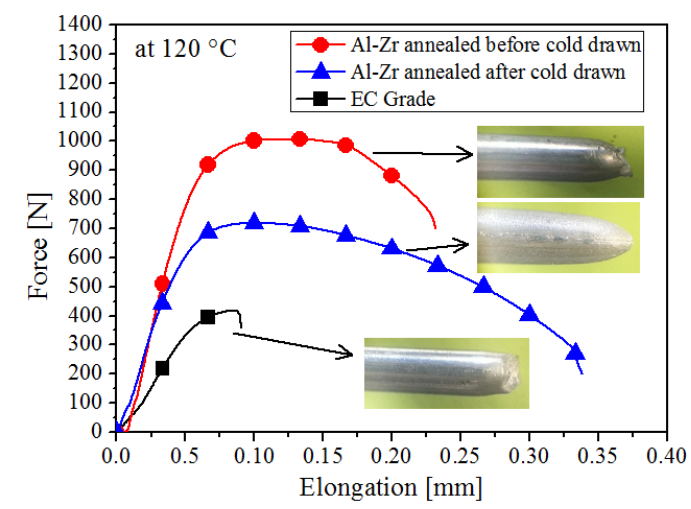

Fig. 1. Force versus elongation graphs of the wires.

It is revealed that there is a significant change both in tensile load and elongation values among the wires. From the tensile test there is a distinct relationship between the presence of $\mathrm{Zr}$ and the amount of force needed for the wire specimen to deform at $120{ }^{\circ} \mathrm{C}$. When comparing the annealing types, the application before cold drawn increases the strength, but reduces the elongation at break value. It is clear from the results that $\mathrm{Zr}$ inoculated wires show higher tensile force and elongation limit, whereas EC grade wire is weak and fragile. This distinguishes that when designing a transmission line under higher current carrying condition (at $120{ }^{\circ} \mathrm{C}$ ) it is best to use Al-Zr alloy wire that is annealed before cold drawn possible for the security of energy supply and for maximum lifespan.

Electrical Resistivity of the Wires at $20{ }^{\circ} \mathrm{C}$. TABLE II

\begin{tabular}{c|c|c|c}
\hline \hline & EC & $\begin{array}{c}\text { Al-Zr annealed } \\
\text { before cold drawn }\end{array}$ & $\begin{array}{c}\text { Al-Zr annealed } \\
\text { after cold drawn }\end{array}$ \\
\hline$\rho\left[\Omega \mathrm{m}^{2} / \mathrm{m}\right]$ & 0.028 & 0.03246 & 0.03060 \\
IACS [\%] & 61.0140 & 53.1242 & 56.3457
\end{tabular}

Table II presents the change in resistivity and IACS value of nearly pure aluminum and two different annealing type of Al-Zr alloy wires. The Northeim's rule is valid to appreciate resistivity behavior of materials [9]. It depends on the type and content of indredients that bases on the following formula:

$$
\rho\left(20^{\circ} C\right)=\rho_{0}+\rho_{i}\left(20^{\circ} C\right)+\Delta \rho_{0},
$$

in which for calculation it is assumed that $\Delta \rho_{0}=\sum_{j} \mathrm{~A}_{j} \mathrm{C}_{j}, \quad \mathrm{~A}$ is the coefficient that relates any element's effect, and $\mathrm{C}$ stands for elemental concentration in wt.\%. Therefore, the $\mathrm{Zr}$ inoculated wires showed a barely large resistivity values due to the rising impurities in Table II. Because of the EC grade aluminum alloys for conductor material represent mainly low alloy element, mechanical properties of wires produced with these alloys are similar to made with pure aluminum and their resistivity is only slightly higher. The ultimate electrical conductivity of among the Al- $\mathrm{Zr}$ wires at the level of $56.35 \%$ IACS was reached in the course of annealed after cold drawn route.

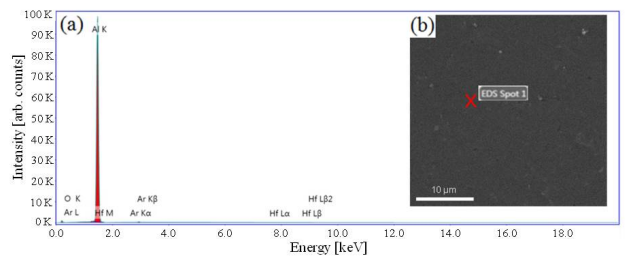

Fig. 2. Sem image of nearly pure Al (a) and its EDS analysis (b).

SEM and EDS analysis in Fig. 2a and b indicated that the EC grade wire material was nearly pure, although some impurities formed in the solid state. The microstructural investigation and an EDS patern of Al$\mathrm{Zr}$ can be seen in Fig. 3a and b. It has been found that addition of $0.32 \%$ wt $\mathrm{Zr}$ decomposes in solid solution and also forms their precipitate $\mathrm{Al}_{3} \mathrm{Zr}$ in nanosize during ageing process. These precipitates get a key role in the microstructural features of the wire material through the increasing recrystallization resistance $[10,11]$. Distribution of $\mathrm{Al}_{3} \mathrm{Zr}$ precipitates can be seen in Fig. 3b. This figure also shows some of the $\mathrm{Al}_{3} \mathrm{Zr}$ precipitates located at the grain boundaries with other intermetallics which are mainly Al-Fe-Si phases in the Al-Zr alloy [12]. Taking 
place at boundaries of $\mathrm{Al}_{3} \mathrm{Zr}$ was verified by EDS patern in Fig. 3a. OM images of two types wire material can be seen in Fig. $4 a$ and b.

$\mathrm{Zr}$ is peritectic with $\mathrm{Al}$ and the maximum solubility of it in aluminum is $0.28 \%$ wt. The Hf existed in Fig. 3a. Because $\mathrm{Zr}$ and $\mathrm{Hf}$ are always found together in natural combinations and are two difficult elements to separate. The content of $\mathrm{Fe}$ probably form in pure $\mathrm{Al}$ as $\mathrm{Al}_{3} \mathrm{Fe}$. Fe has no effect on the solubility of $\mathrm{Zr}$ in $\mathrm{Al}$ or on the precipitation. While it is reported by Hallem et al. [13] that the Si content affect precipitation in Al-Zr alloys. So that cautions should be taken when $\mathrm{Si}$ is added to these types of alloys.

The Al-Zr alloy wire material which after thermomechanical processing (extrusion+cold drawn) was able to withstand $120^{\circ} \mathrm{C}$. High temperature characteristics of the Al-Zr alloy is well explained by the existence of dispersoids in aluminum matris for controlling microstructure through the control of recovery, recrystallisation and grain growth $[14,15]$. Dynamic recovery which is a thermaly activated transform is suppressed on cold drawn process and the wire material work harden, making it more difficult to deform.

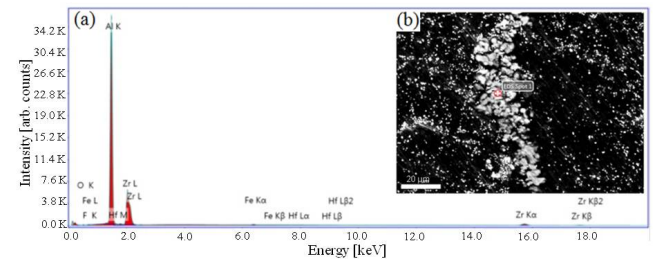

Fig. 3. SEM image of Al-Zr alloy (a) and its EDS analysis (b).

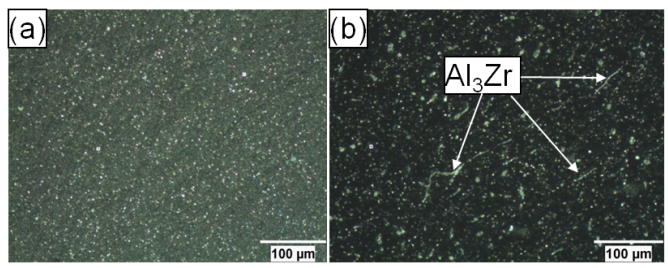

Fig. 4. Microstructure images of (a) Al, (b) Al-Zr alloy.

This condition reflected in the microstructure as smaller grains and cold worked wire recrystallize easily. Recrystallization in materials containing second phase particles is affected by two mechanisms. The first mechanism is about particle distribution that larger than $1 \mu \mathrm{m}$ and non-deformable particles are development location for recrystallization nuclei [16]. Thus, recrystallization can be controlled through particle distribution. Small and near dispersed particles cause a preventation or a slowing effect on recrystallization. This is the second mechanism, called Zener drag [10]. First extrusion and after cold drawn proceses the Al-Zr wire material was in a deformed state where it was gained strength through strain hardening. Zr formed finely dispersed precipitates with $\mathrm{Al}$ which were important to prevent recrstallisation in $\mathrm{Al}-\mathrm{Zr}$ wire materials. Heterogenous tufts of $\mathrm{Al}_{3} \mathrm{Zr}$ on boundaries were observed in Fig. 3b. During extrusion and cold drawn processing the existence of fine spherical and metastable $\mathrm{Al}_{3} \mathrm{Zr}$ phases were the most effective dispersoids of to prevent recrystallization in the aluminum alloy [17]. The inhibitor characteristics of it is explaned by pinning the grain boundaries [18].

\section{Conclusion}

In summary, the effects of $\mathrm{Zr}$ on the tensile and electrical properties of Al-0.32 $\mathrm{Zr}$ (wt.\%) thermal-resistant alloy was investigated on condition that two types annealing procedure were conducted as after and before cold drawn on the wire manufacturing. Zr inoculation resulted in the increasing strength and decreasing conductivity, while the anneling before cold drawn procedure improved this characterictics more than the other route. Microstructure observation shows that the apparent improvement of strength should be mainly associated with the formation of finer $\mathrm{Al}_{3} \mathrm{Zr}$ precipitates and substructure with boundaries pinned by nano-sized precipitates. As a result the Al-0.32 Zr (wt.\%) thermal-resistant alloy wire is annealed before cold drawn possible for the security of energy supply and for maximum lifespan.

\section{References}

[1] A. Soares, A. Gomes, C.H. Antunes, Renew. Sust. Energ. Rev. 30, 490 (2014).

[2] M. Hsu, Utilities Policy 6, 257 (1997).

[3] W. Yuan, Z. Liang, C. Zhang, L. Wei, Mater. Des. 34, 788 (2012).

[4] S. Karabay, Mater. Des. 27, 821 (2006).

[5] S. Karabay, Mater. Des. 29, 1364 (2008).

[6] C.A. Cimini Jr, B.Q.A. Fonseca, Int. J. Elec. Power. 49, 280 (2013).

[7] S.Karabay, E.A. Güven, A.T. Ertürk, Eng. Fail. Anal. 31, 153 (2013).

[8] S.Karabay, E.A. Güven, A.T. Ertürk, Materiali In Tehnologije 47, 119 (2013).

[9] A.L. Norbury, Trans. Faraday Soc. 16, 570 (1921).

[10] B. Forbord, H. Hallem, J. Røyset, K. Marthinsen, Mater. Sci. Eng. A. 475, 241 (2008).

[11] B. Forbord, H. Hallem, J. Røyset, K. Marthinsen, Mater. Sci. Eng. A. 387, 936 (2004).

[12] E. Feyzullahoğlu, A.T. Ertürk, E.A. Güven, T. Nonferr. Metal. Soc. 23, 3575 (2013).

[13] H. Hallem, W. Lefebvre, B. Forbord, F. Danoix, K. Marthinsen, Mater. Sci. Eng. A. 421, 154 (2006).

[14] B. Forbord, L. Auran, W. Lefebvre, H. Hallem, K. Marthinsen, Mater. Sci. Eng. A. 424, 174 (2006).

[15] J. Zhi-Hong, J. Røyset, J.K. Solberg, L. Qing, T. Nonferr. Metal. Soc. 22, 1688 (2012).

[16] Y.W. Riddle, T.H. Jr Sanders, Mater. Sci. Forum 331, 799 (2000).

[17] G. Peng, K. Chen, H. Fang, S. Chen, Mater. Sci. Eng. A. 535, 311 (2012).

[18] Y. Birol, E.A. Güven, L.J. Capan, Mater. Sci. TechLond. 27, 1851 (2011). 